\title{
Coupling of Supercritical Fluid Extraction with Chromatography
}

\author{
Kiyokatsu JiNNo* and Muneo SAITo** \\ *School of Materials Science, Toyohashi University of Technology, Toyohashi 441, Japan \\ **JASCO Japan Spectroscopic Co., Ltd., Hachioji 192, Japan
}

\begin{abstract}
Coupling methods between supercritical fluid extraction (SFE) and various chromatographic techniques have been reviewed. Developments using supercritical fluids in chromatography have been tremendous and a confirmation of the usefulness of this technique (called supercritical fluid chromatography (SFC)) has been evidenced by many scientists. Another field using supercritical fluids in analytical processes is SFE. Since SFE has many advantages compared to conventional solvent extraction method, such as faster and better controllability of conditions, no requirements for solvent waste and lower cost, popularity has been recently increasing. The most promising and favorable advantage of SFE is, however, the possibility to directly combine the extraction process to additional separation processes. The combination of SFE and various chromatographic techniques can be established more easily than the conventional solvent extraction technique. This review will mainly describe the potential of SFE, especially focusing on the coupling of SFE with chromatographic techniques. The review on SFC is also included since SFC is the major technique in which supercritical fluids are effectively used and no discussion concerning SFE is possible without knowledge about SFC.
\end{abstract}

Keywords Supercritical fluid extraction, supercritical fluid chromatography

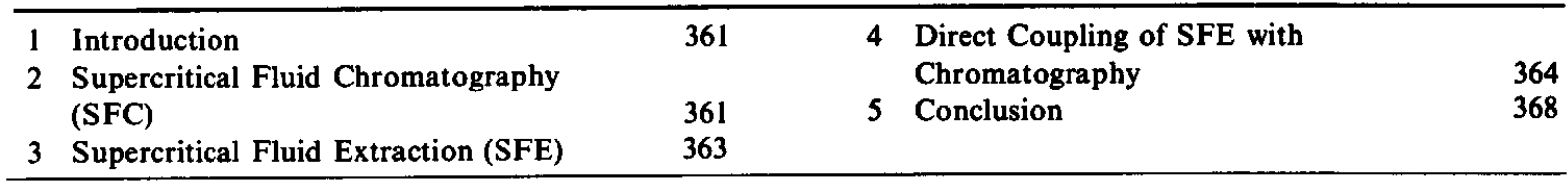

\section{Introduction}

Hannay and Hogarth (1879) ${ }^{1}$ first reported that supercritical fluids, or dense gases, have a solvating power more than one century ago. However, in practice, only two major applications of supercritical fluids to analytical chemistry have been tried since the 1960s. These are:

1) Supercritical Fluid Chromatography (SFC) and

2) Supercritical Fluid Extraction (SFE).

This review mainly describes the potential of SFE in analytical chemistry, especially focusing on the coupling of SFE with chromatographic separation techniques. However, we must also discuss SFC for two reasons: SFC is the major technique in which supercritical fluids are effectively used and, historically, the potential of SFE can not be discussed without knowledge of SFC. A number of books have recently been published concerning SFE and SFC; ${ }^{2-5}$ if someone would like more information, the reference to these publications should be helpful.

\section{Supercritical Fluid Chromatography (SFC)}

SFC that uses a supercritical fluid as the mobile phase was introduced by Klesper, Corwin and Turner ${ }^{6}$ as high-pressure gas chromatography. Since then, SFC has been investigated by several research groups. The development of SFC can be roughly classified in two stages: the first stage took place in the $60 \mathrm{~s}$, and the second stage in the 80 s.

Concerning the first stage, SFC was developed by several research groups: Klesper et al:; ${ }^{6} \mathrm{Klesper}$ and Hartmann; 7,8 Hartmann and Klesper; 9 Myers and Giddings; ${ }^{10-12} \mathrm{Sie}$ and Rijnders; ${ }^{13-17}$ Karayannis et al: ${ }^{18-21}$ Giddings et al.:22 Jentoft and Gouw; ${ }^{23,24}$ Novotny et al:;5 Bartmann and Schneider; ${ }^{26,27}$ and others. Various fluids were used as the supercritical mobile phase, e.g., carbon dioxide, ammonia, sulfur dioxide, alcohols, chlorofluoromethanes and low-boiling-point hydrocarbons. Most of the columns that were used were of $1 / 8$ or $1 / 4$ in. stainless-steel tubes packed with GC adsorbents, except for 1/16 in. micro columns used by Giddings et al..$^{22}$ for high-inlet-pressure 
GC. The most widely used detector in SFC is the UV absorption detector with some modifications, including a high-pressure cell for using fluids which produce the gas phase at atmospheric pressure, and a cooled cell for using fluids which become liquid at lower temperature under atmospheric pressure. Flame ionization detectors (FID) were examined by Sie et al.;14 Myers et $a l . ;^{12}$ and Bartman. ${ }^{28}$ The use of a mass spectrometer as an SFC detector was examined by Randall. ${ }^{29}$

There have been excellent reviews by Gouw and Jentoft; ${ }^{30-32}$ Klesper $^{33}$, Van Wasen et al. ${ }^{34}$ These cover developments in this field, including the principle, instrumentation and applications on the first stage. Randall ${ }^{35}$ covers SFE as well as SFC in impetus for DGC-MS (dense gas chromatography-mass spectrometry) or SFC-MS in terms of the present technology.

In spite of the great efforts of these researchers, SFC did not obtain success in attracting many practical chromatographers to take up the. use of this technique as an analytical tool. This was because SFC was considered to be a technique still under development and there was much to be investigated at that time.

In the early $1980 \mathrm{~s}$, advances in micro-HPLC renewed interest in SFC and the second stage started. A rapid mass transfer in supercritical media attracted researchers, since it offers high-speed separation with high resolution on an open tubular capillary column (less than $100 \mu \mathrm{m}$ i.d.) $)^{36}$, which was not very successful in liquid chromatography, because of a slow mass transfer, and also on a packed capillary column (less than $1 \mathrm{~mm}$ i.d.). The small consumption of fluid encouraged chromatographers to use inflammable (even toxic), and very expensive fluids under both high pressure and temperature. A very expensive fluid, such as xenon, was examined regarding its feasibility in SFC-FTIR by French and Novotny. ${ }^{37}$ Thus, extensive research work on capillary column SFC has been carried out by several groups: Smith et al. ${ }^{38,39}$, Peaden and $\mathrm{Lee}^{40}$, Springston and Novotny ${ }^{41}$, Fjeldsted and Lee $^{42}$, Hirata and Nakata ${ }^{43}$, Takeuchi et al. ${ }^{44}$ Peaden and $\mathrm{Lee}^{45}$ reviewed the developments in the first stage and foresaw the second stage of SFC developments.

There are several research groups which have used conventional-size $(2-6 \mathrm{~mm}$ i.d.) packed columns in SFC. Gere et al. ${ }^{46}$ reported a sophisticated SFC system based on HPLC instrumentation. Norris and Rawdon ${ }^{47}$, and Rawdon ${ }^{48}$ investigated the flame ionization detector (FID) in an SFC system based on HPLC hardware, and applied it to the determination of hydrocarbon types in petroleum lipids. Saito ${ }^{49}$, Sugiyama ${ }^{50}$ and their co-workers examined the direct coupling of SFE with SFC and analyzed the caffeine contents in a carbon dioxide extract of roasted coffee beans. Jinno et al. ${ }^{51-53}$ investigated the retention prediction of polycyclic aromatic hydrocarbons (PAHs) on a silica-ODS column. Hara et al. ${ }^{54,55}$ separated enantiomers on a homemade column with carbon dioxide as a mobile phase.

In addition to the use of a simple UV detector with a high-pressure cell, combinations of SFC with new detectors have also been investigated. These are as follows: SFC/UV spectrometry using a photodiodearray multiwavelength UV detector by Saito ${ }^{49}$, Sugiyama and co-workers ${ }^{50}$, Jinno et al.;1-53 SFC/mass spectrometry (SFC/MS) by Smith et al. ${ }^{38,39}$, and Crowther and Henion; ${ }^{56}$ SFC/Fourier transform infrared spectrometry (SFC/FTIR) by Shafer and Griffiths ${ }^{57}$, Olesik et al.; ${ }^{58}$, Johnson et al.; ${ }^{59} \mathrm{SFC} /$ infrared spectrometry based on the buffer memory technique by Fujimoto et al:;0 and SFC/diffuse reflectance (DR)-FTIR by Shafer $e t$ al. ${ }^{61}$ Several review articles have been published concerning the coupling of SFC with molecular spectroscopy, such as MS ${ }^{62,63}$ and IR. ${ }^{64}$ New trends in using atomic emission spectroscopic techniques have also been published. Microwave-induced plasma emission detection (MIP) has been combined with SFC to obtain element specific information by Novotny et al.; ${ }^{65,66}$ Lee's group tried to use radio-frequency plasma detection in capillary SFC. ${ }^{67}$ Inductively coupled plasma detection (ICP) was also evaluated as allowing element-selective detection in SFC by Olesik and Olesik ${ }^{68}$, Jinno and coworkers $^{69-71}$ and Uden et al. ${ }^{72}$

At the present, SFC exhibits two major currents:

1) packed column SFC

2) capillary column SFC (open tubular or packed).

In packed column SFC, the possibilities of sample fractionation and collection could be regarded as one of the advantages in SFC using a fluid that is in the gas phase at atmospheric pressure, such as carbon dioxide, since using such a mobile phase may allow an easy separation of solutes from the column effluent. In 1972, Jentoft and Gouw ${ }^{24}$ investigated fractionation in SFC by using a fraction collector enclosed in a highpressure vessel pressurized with nitrogen gas. Klesper and Hartmann ${ }^{73}$ reported a sophisticated SFC system for the fractionation of the styrene oligomer. Campbell and $\mathrm{Lee}^{74}$, and Nishioka et al. ${ }^{75}$ also reported the fractionation of petroleum- and coal-derivative mixtures by using a similar system.

During the last few years, the potential of the separation capability of open tubular and packed capillary column SFC with FID has been stressed by several research groups. Schoenmakers ${ }^{76}$ discussed theoretical comparisons of open tubular and packed capillary columns. Petersen covered the use of packed columns in SFC regarding instrumentation, detection, mobile phases, stationary phases and applications. ${ }^{77}$ Janssen and $\mathrm{Cramers}^{78}$ treated the theoretical points of SFC in view of a comparison of open tubular columns with packed columns. They concluded that; the plate number per bar pressure drop is much higher in open tubular capillary columns, but that the practical number of plates generated per second, however, favors the use of packed columns. This means that a packed column offers sufficient efficiency to separate most samples in a shorter period of time than an open tubular column. However, if one wishes to separate a complex mixture sample with higher efficiency, an open tubular column that requires a longer analysis time 
must be used. A considerable reduction in the inner diameter of open tubular capillary columns is needed in order to obtain a similar analysis speed proposed by packed columns. The extremely low sample capacity and the stringent requirements placed on sample introduction and the detection system is currently of major concern regarding the use of capillary columns with smaller inner diameters for instrumentation, although a definite advantage of capillary columns is that relatively polar solutes can be eluted without the addition of modifiers due to the high degree of surface deactivation of the columns. A capillary column SFC is believed to be a more powerful chromatographic techniques regarding efficiency and resolution, compared with HPLC; it can also deal with higher-molecular-weight compounds and thermally labile compounds which can not be analyzed by gas chromatography (GC). Therefore, a number of instrument companies are now in this business.

\section{Supercritical Fluid Extraction (SFE)}

Although supercritical fluids do not have any advantages over liquid solvents regarding solvating power, the following several merits of the properties of supercritical fluids (compared with those of liquid solvents) demonstrate the potential for SFE to approach the idealized for analytical extraction: 1) SFE is fast because of better mass transfer characteristics caused by higher solute diffusivities and lower viscosities of supercritical fluids than liquid solvents; 2) the solvent strength of a supercritical fluid can easily be controlled since the solubility depends on the pressure and temperature used for the extraction; 3) many supercritical fluids are gases under ambient conditions, and the concentration steps after SFE are greatly simplified and direct coupling of the SFE step to chromatographic techniques is facilitated; and 4) most supercritical fluids are relatively inert, pure, nontoxic and inexpensive and the generation of liquid waste solvents and the exposure of laboratory personal to toxic solvents can be avoided.

SFE was introduced by Zosel ${ }^{79}$ in 1963. Since then, this method has been developing as an industrial-scale extraction technique reported by many research groups, such as: Hubert and Vitzthum; ${ }^{80}$ Peter and Brunner; ${ }^{81}$ Eggers and Tschiersch; ${ }^{82}$ Stahl et al.;83,84 Coenen and Rinza; ${ }^{85}$ Brogle; ${ }^{86}$ Filippi; ${ }^{87}$ Bott $;{ }^{88}$ Vollbrecht; ${ }^{89}$ Calame and Steiner; ${ }^{90}$ Gardner; ${ }^{11}$ Friedrich and Pryde; ${ }^{92}$ and others. There have been extensive review articles. Randall ${ }^{29}$ covered not only SFE but also SFC, and Williams ${ }^{93}$ discussed the principles, instrumentation and applications of SFE to industry. Brunner and Peter ${ }^{94}$ published a large collection of extraction data of various substances. There are also excellent books edited by Schneider et al..$^{95}$, and by Penninger et al. ${ }^{96}$, including practical applications, and process design, as well a monograph by McHugh and Krukonis ${ }^{97}$ with a broad patent review of SFE and a computer program for the calculation of phase behavior.

For obtaining better SFE performance, the extract must be subjected to further analysis and examined if the target components are to be efficiently extracted by optimizing the extraction conditions, i.e., suitable pressure or density as well as fluid temperature. For such a purpose, chromatography is the most essential technique; various types of chromatography such as thin-layer chromatography (TLC), GC and HPLC have been employed. The extracts have traditionally been analyzed by an off-line technique after collection, since the SFE system generally used was a pilot plant and the primary function of the system was to collect the extract but not to perform an analysis. The analysis has thus been regarded as a different process in most cases.

Table 1 shows the critical temperatures and pressures of various fluids appearing in the references regarding SFC and SFE.

Among the variety of supercritical fluids, carbon dioxide is the most widely used, especially in SFE, since it is inexpensive, non-toxic, non-flammable and has a low critical temperature $\left(31.3^{\circ} \mathrm{C}\right)$, and pressure $(72.9$ atm). In some cases in capillary SFC, ammonia, xenon, hydrocarbons, nitrous oxide have been examined as supercritical mobile phases.

Table 1 Critical temperatures $\left(T_{\mathrm{c}}\right)$ and pressures $\left(P_{\mathrm{c}}\right)$ of various fluids used in SFE and SFC

\begin{tabular}{lrc}
\hline \multicolumn{1}{c}{ Fluid } & $T_{\mathrm{c}} /{ }^{\circ} \mathrm{C}$ & $P_{\mathrm{c}} /$ atm \\
\hline Ammonia & 132.3 & 11.3 \\
Benzene & 288.9 & 48.3 \\
Carbon dioxide & 31.3 & 72.9 \\
Chlorotrifluoromethane & 28.8 & 39.0 \\
Hexane & 234.2 & 29.6 \\
Nitrous oxide & 36.5 & 71.4 \\
Pentane & 196.6 & 33.3 \\
Propane & 96.8 & 42.0 \\
Xenon & 16.6 & 58.0 \\
\hline
\end{tabular}

Table 2 Recent trends in the application of supercritical fluids

\begin{tabular}{ccc}
\hline Method & $\begin{array}{c}\text { Separation } \\
\text { technique }\end{array}$ & Application \\
\hline $\begin{array}{c}\text { Pressure } \\
\text { change } \\
\text { Eemperature } \\
\text { change } \\
\text { Adsorbent } \\
\text { column }\end{array}$ & Fractionation \\
Chromatography & $\begin{array}{c}\text { Packed } \\
\text { column }\end{array}$ & Analytical SFC \\
Capillary \\
column
\end{tabular}


In SFE, fractionation has been carried out by changing mainly the pressure and/or temperature. In order to isolate the target compound from the extract, an activated carbon adsorbent column was used by Zosel. ${ }^{98}$ Recently, Arai and Saito ${ }^{99}$ enriched unsaturated fatty acid methyl esters from sardine oil using a urea column by forming clathrate compounds. Although present industrial SFE systems are quite different from analytical SFC systems, they have many things in common and their applications overlap each other, for improving separation capability. Table 2 summarizes the recent application trends regarding supercritical fluids.

General review articles concerning SFE have been written by Hawthorne ${ }^{100}$ and Chester and Pinkston. ${ }^{101}$

\section{Direct Coupling of SFE with Chromatography}

SFE can reduce the time regarding for the quantitative extraction and recovery of analytes from a wide variety of samples, as much as several orders of magnitude over the time required by conventional liquid extraction techniques. In addition to this important advantage, the use of supercritical fluids eliminate the generation of large volumes of waste solvents and greatly simplifies the concentration of extracted analytes. The latter advantage can realize a combination of SFE to various chromatographic techniques directly, which is useful when maximum sensitivity is required from small samples and when the elimination of sample handling between extraction and chromatography is desirable.

Stahl and Schilz ${ }^{102}$ reported a system which combines SFE with TLC. This system has a sophisticated fluid delivery, a microautoclave for extraction and a special thin-layer chromatograph incorporated. The TLC plate is arranged so as to receive the extract via a very fine capillary tube, and also to move back and forth so that the extracted substances can be deposited as a starting band of $2 \mathrm{~cm}$. The fluid delivery section consists of a diaphragm compressor, a heat-exchange coil, a backpressure regulator, a precision manometer and peripheral devices.

Extraction is carried out by stepwise pressure increase so that different fractions of the extract at different pressures can be deposited on the TLC plate as consecutive starting bands. Stahl et al. ${ }^{83,84,103}$ used this system to carry out extensive reseach on the extraction of various substances.

Unger and Roumeliotis ${ }^{104}$ reported a coupling unit that allows on-line operation of SFE with HPLC. The main part of the unit consists of two six-way valves (4 and 8), two microbore columns (7) serving as an extract trap and loop, and peripheral devices, as shown in Fig. 1. The extraction vessels used were 0.4 and $10 \mathrm{ml}$ in volumes in accordance with the sample size. The operation procedure of the system is in three steps: release, load and inject, where each step is carried out

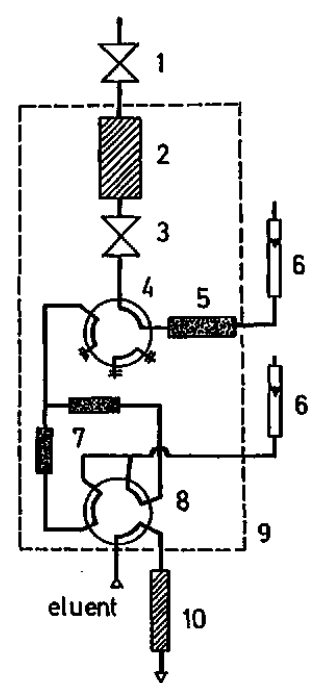

Fig. I Schematic diagram of the coupling unit for SFE/ HPLC by Unger and Roumeliotis (1983). ${ }^{104}$ 1) back-pressure regulator; 2) extraction vessel; 3) high-pressure twoway angle valve; 4) six-port external sample valve; 5) packed microbore column for the release and waste deposit; 6) rotameter; 7) microbore columns, serving for depositing and as a loop; 8) sample injector; 9) thermostat; and 10) HPLC column.

by switching the two of six-way valves (4 and 8 ).

In the release operation, an expansion of loaded carbon dioxide takes place along the waste column (5) and vents out to atmospheric pressure via the rotameter (6). The extraction speed and separation in this part is regulated by the length, inner diameter of the column, and the particle size of the packing material.

During the load operation, by switching a valve (4), the extract flows through both of the packed microbore columns (7), to the sample injector (8), then vents out to the atmosphere via the rotameter (6). The microbore columns play both the role of sampling and a loop of the sample injector (8). The time required for extract loading is 10 to $60 \mathrm{~s}$. The sample mass deposited on the columns is controlled by the loading period.

Injection is carried out by switching the injector (8) after switching the valve (4) back to the release position and decreasing the pressure in the loop to atmospheric pressure; the extract deposited on the columns (7) is then eluted by an eluent and introduced into an HPLC column (10) of $4 \mathrm{~mm}$ i.d. $\times 120 \mathrm{~mm}$ length.

Unger and Roumeliotis tested the system by extracting valepotriates from Radix valerianae at $313^{\circ} \mathrm{K}$ temperature and $96 \mathrm{~atm}$ pressure.

Hawthorne and Miller ${ }^{105}$ assembled an SFE system using ordinary HPLC fittings, a union as an extraction vessel, and a commercial supercritical fluid pumping system for capillary SFC. Direct coupling is accomplished by simply inserting the pressure restrictor tube used for applying extraction pressure to the vessel into the on-column injector port of the capillary gas 


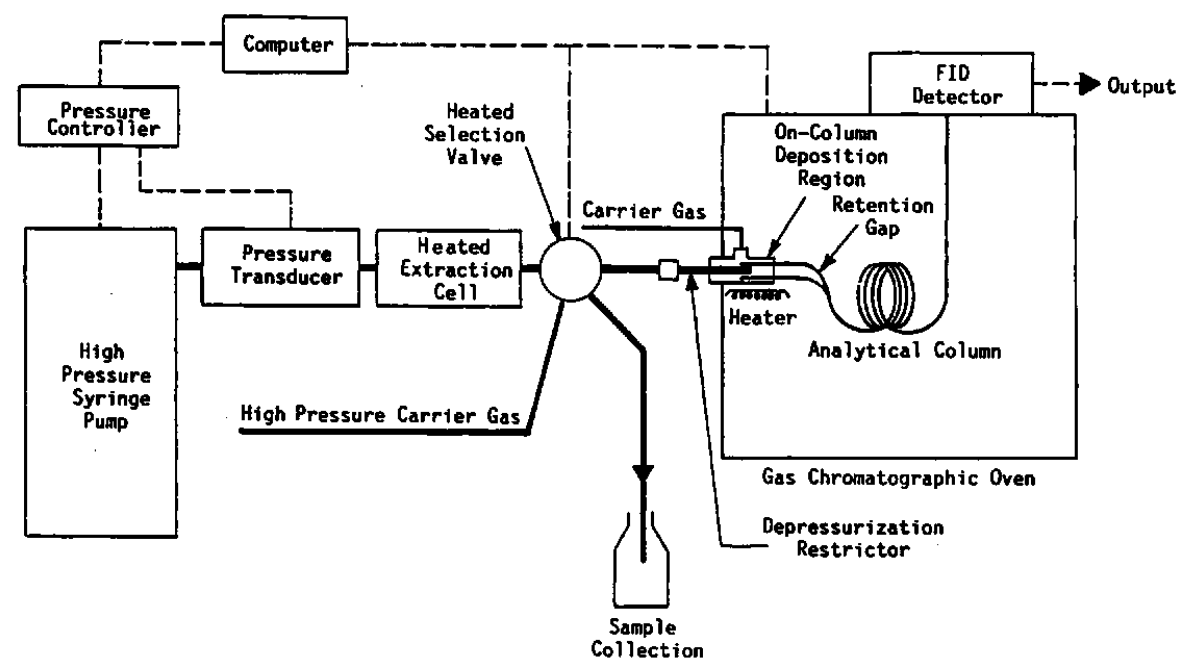

Fig. 2 Schematic diagram of coupled SFE/capillary GC by Wright et al. (1987). ${ }^{106}$

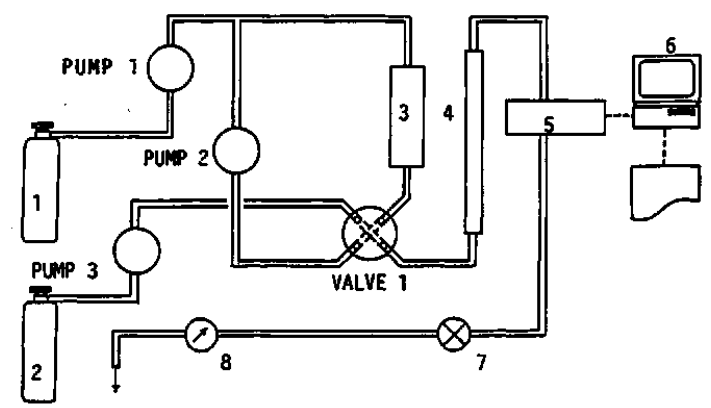

Fig. 3 Schematic diagram of coupled SFE/SFC in parallel by Saito et al. (1986). ${ }^{107}$ 1, 2) carbon dioxide cylinder; 3) extraction vessel; 4) separation column; 5) photo-diode-array multiwavelength UV detector; 6) data processor; 7) backpressure regulator; 8) mass flowmeter.

chromatograph used. They examined the extraction of PAHs and polychlorinated biphenyls (PCBs) from environmental solids with nitrous oxide as an extraction media.

Figure 2 shows a schematic illustration of an on-line SFC-capillary GC system developed by Wright $e$ et al. ${ }^{106}$ Although the system is a little more complicated than that of Hawthorne and Miller ${ }^{105}$, it is equipped with a selection valve for sample collection. They also examined the extraction of environmental samples, though the fluid used was only carbon dioxide.

There are two possible methods of coupling SFE with SFC:

1) coupling in parallel

2) coupling in series.

Although a parallel connection requires separate SFE and SFC system, such a system is useful for on-line monitoring of a pilot plant or even an industrial-scale SFE plant.

Figure 3 shows the parallel SFE/SFC reported by
Saito et al. ${ }^{107}$ They added an extra fluid delivery system and an in-line pump to a series SFE/SFC system. The SFE section comprises a carbon dioxide cylinder (1), PUMP 1, extraction vessel (3), VALVE 1 with an internal sample loop of $1 \mu \mathrm{l}$ and PUMP 2. PUMP 1 pressurizes a closed loop of the line where the extraction vessel (3), VALVE 1 and PUMP 2 are placed in series. Once the closed line has been pressurized by PUMP 1, which is operated in the constant pressure mode, carbon dioxide is recycled by PUMP 2. Carbon dioxide containing the extract flows through the sample loop continuously, and injection to the SFC section can be made by switching VALVE 1 at the desired time after extraction has been started. The sample loop $(1 \mu \mathrm{l})$ is of negligible volume compared to the volume of the extraction vessel (3), $2 \mathrm{ml}$, plus the associated volumes of the line and hydraulic components.

The SFC section comprises PUMP 3, a microbore separation column (4) of $0.8 \mathrm{~mm}$ i.d. $\times 50 \mathrm{~mm}$ length, a detection system $(5,6)$, a back-pressure regulator (7) and a mass flowmeter (8). The SFC section is connected with the SFE section via VALVE 1. The extraction vessel, separation column, back-pressure regulator, etc. are thermostated in an oven.

The detection system comprises a photo-diode-array multiwavelength UV detector (5) with a high-pressure cell (which withstands $300-\mathrm{kg} / \mathrm{cm}^{2}$ pressure) and a data processor (6) (which permits real time monitoring of UV spectra as a function of time ${ }^{108,109}$ ).

The use of SFC in the above-mentioned manner enables a simultaneous quantitation of multicomponents in a supercritical fluid under the same condition, pressure and temperature at the detector, irrespective of the extraction pressure and temperature. This is quite essential to quantify solutes in a supercritical fluid by spectroscopy for the measurement of phase equilibrium, since the fluid spectra may be changed by such parameters as pressure (density) and temperature. 


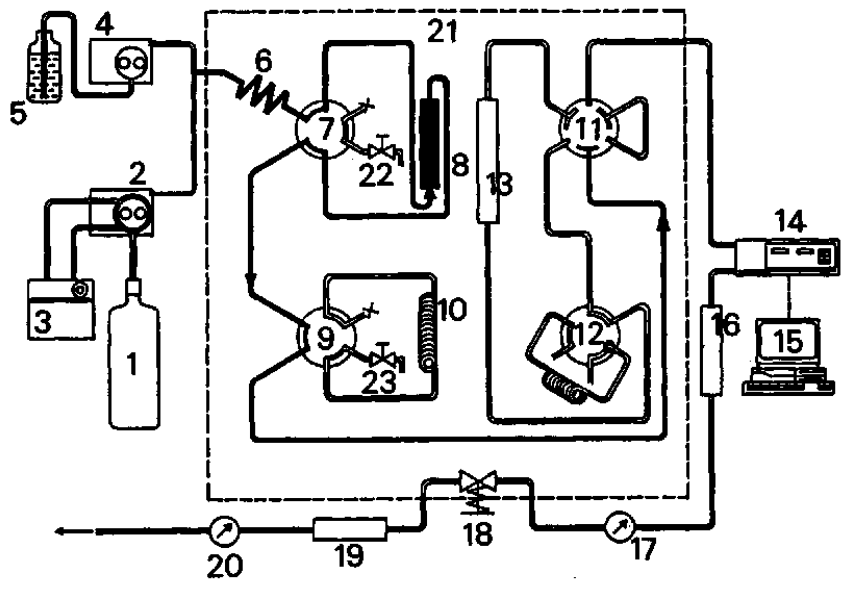

Fig. 4 Hydraulic diagram of directly coupled SFE/SFC and flow line for SFE operation. 1) carbon dioxide cylinder; 2) liquefied carbon dioxide delivery pump; 3) coolant circulating bath; 4) modifier delivery pump; 5) modifier solvent reservoir; 6) heat exchanger coil; 7) six-way valve for by-passing extraction vessel; 8) extraction vessel; 9) six-way valve for by-passing trap loop; 10) extract trap loop; 11) sixway valve for by-passing injector and separation column; 12) injector; 13) separation column; 14) multiwavelength detector; 15) data processor; 16) extract trap column; 17) back-pressure gauge; 18) back-pressure regulator; 19) trap for mass flowmeter; 20) mass flowmeter; 21) oven; 22) vent valve for extraction vessel used for collecting extract; and 23) vent valve for trap loop. After SFE, the valve (9) is switched to load the extract trap loop (10) with the extract. The valve is then switched back to by-pass the loop for pre-pressurization and equilibration of the separation column (13), while the loop holds the extract.

The second coupling method is a series connection of SFE and SFC. Figure 4 shows the hydraulic diagram of the first commercial SFE/SFC system (JASCO Model SUPER-100) based on a system, which Saito ${ }^{49}$, Sugiyama $^{50}$ and co-workers constructed for the direct coupling of SFE with SFC.

This system can be regarded as a double-stage separation analysis method, which includes SFE directly coupled with SFC. In this new method SFE is utilized as the first separation step in a similar way to sample pretreatment in HPLC; SFC is used as the second separation step. This configuration allows the analyst to place a raw and/or solid sample in the system in order to obtain a chromatogram of the sample extract.

The extraction and chromatography of various substances were examined by using the above-mentioned system. The SFE of caffeine from roasted coffee beans and off-line HPLC analysis as well as on-line SFC analysis were reported by Sugiyama et al. ${ }^{110} \mathrm{On}-$ line SFE/SFC and off-line SFE/infrared spectroscopy (IR) analyses of additives in polyvinylchloride were carried out by Imahashi et al.111, vitamin K's from serum by Hondo et al. ${ }^{112}$, tocopherol extraction by Saito and Hondo ${ }^{113}$, and SFE/SFC analysis of PAHs

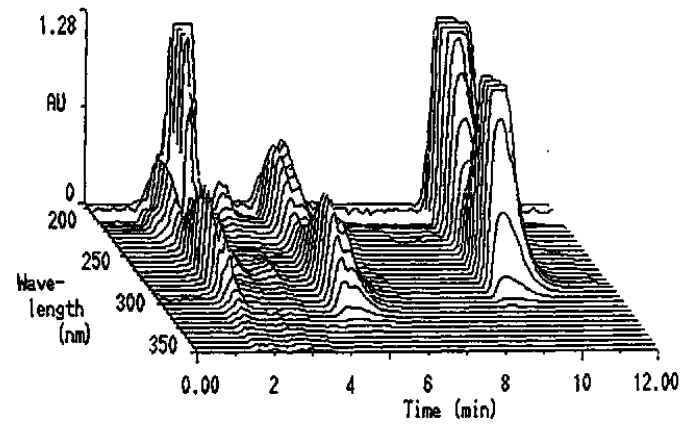

Fig. 5 Three-dimensional SFC chromatogram of the SFE extract of roasted coffee obtained by directly coupled SFE/SFC, after Sugiyama et al. (1985). ${ }^{110}$ Caffeine is eluted at about $8.5 \mathrm{~min}$.

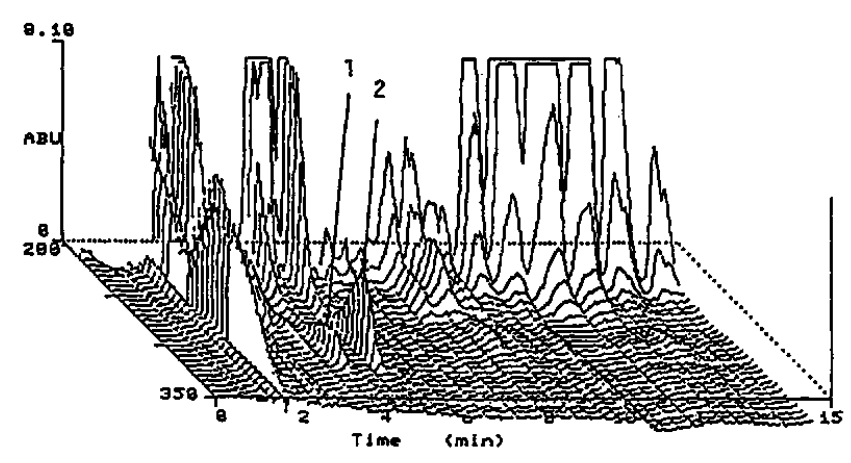

Fig. 6 Three-dimensional SFC chromatogram of SFE extract of wheat germ, after Saito et al. (1987). ${ }^{116}$ Peak assignment: $1=\beta$-tocopherol, $2=\alpha$-tocopherol. ${ }^{116}$

from petroleum pitch by Saito et al. ${ }^{114}$

Figure 5 shows a three-dimensional SFC chromatogram of the extract from roasted coffee beans obtained by directly coupled SFE/SFC with supercritical carbon dioxide.

Figure 6 shows the SFE/SFC chromatograms of wheat germ extract, where $\alpha$ - and $\beta$-tocopherols are clearly found.

As the final part of this review, we describe the possibility of a preparative method for SFC.

As mentioned in the previous section, Jentoft and Gouw $^{24}$ reported on the fractionation system for SFC eighteen years ago. Figure 7 shows a high-pressure fraction collector with carbon dioxide developed by Jentoft and Gouw. A turntable holding six collection vials is enclosed in a high-pressure vessel, which is pressurized with nitrogen gas. Since this arrangement allows the column effluent to be maintained in the liquid state within the vessel, fractionation is accomplished in a similar way as in preparative HPLC.

Recently, Perrut and Jusforgues ${ }^{115}$ reported on a preparative SFC equipped with high-pressure collection vessels which are selected by a switching valve (Fig. 8).

Saito, Hondo and Yamauchi ${ }^{16}$ further developed a 
series SFE/SFC which allows the fractionation of solutes of interest in the extract.

Saito et al. examined tocopherol extraction from wheat germ. Five grams of wheat germ were placed in a 10 -ml extraction vessel $(8 \mathrm{~mm}$ i.d. $\times 200 \mathrm{~mm}$ length); extraction was then performed at $250-\mathrm{kg} / \mathrm{cm}^{2}$ pressure and $40^{\circ} \mathrm{C}$ temperature for one hour, and prep-SFC performed. Figure 9 shows the obtained chromato-

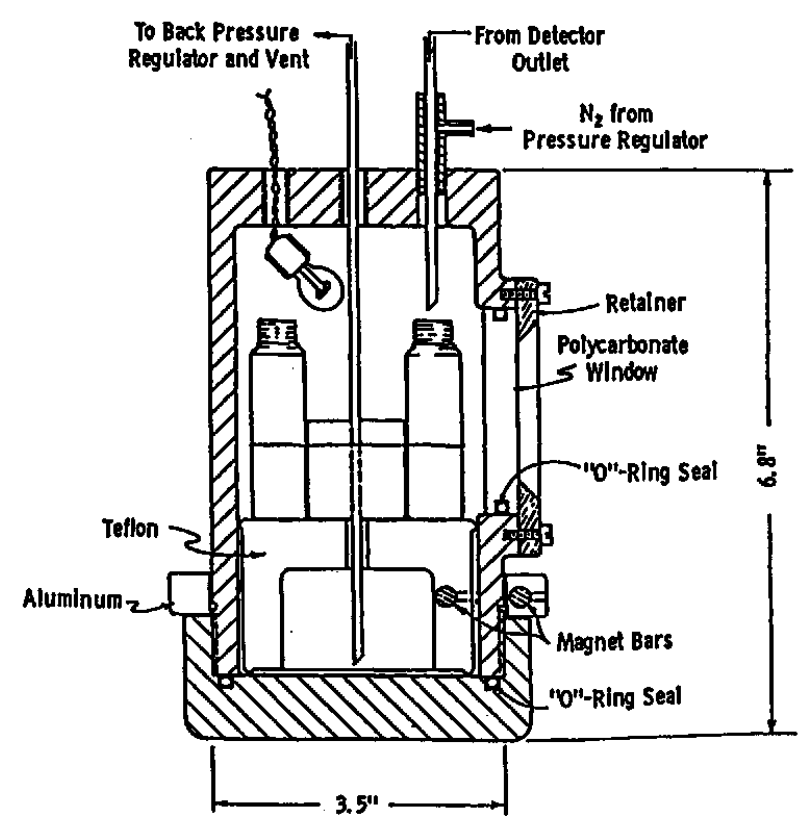

Fig. 7 High-pressure fraction collector developed by Jentoft and Gouw (1972).24 grams monitored at 220,240 and $295 \mathrm{~nm}$. The numbers under the time axis show the time frames and corresponding fractions collected while referring to real-time monitoring of the chromatogram.

Although the enrichment efficiency was not very high, they proved that double-stage SFE/preparative SFC could be useful and that fractionation can be carried out without difficulty in a similar manner as in
THE PSFC CONCEPT
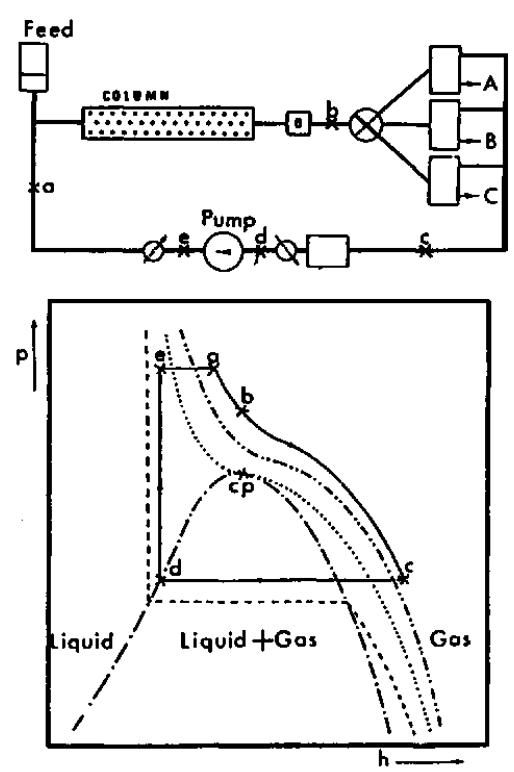

Fig. 8 Schematic diagram of a preparative SFC system by Perrut and Jusforgues (1986). ${ }^{115}$

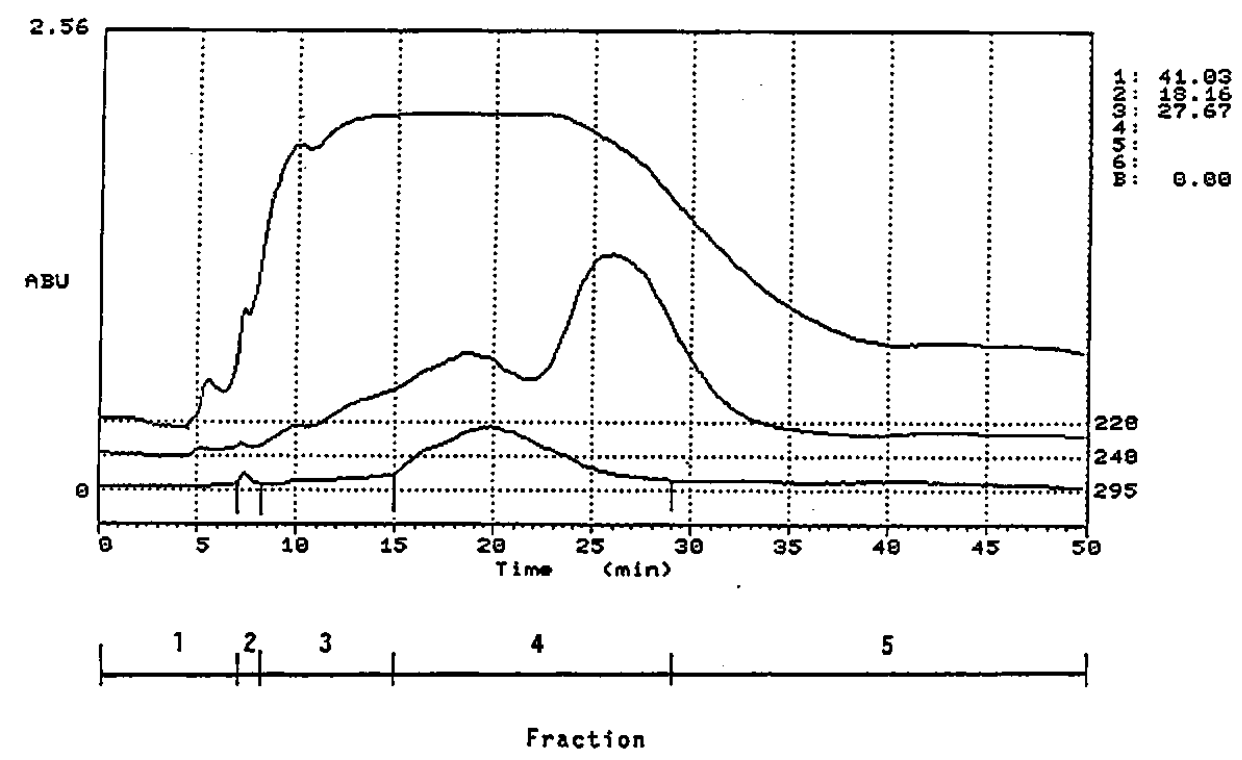

Fig. 9 Chromatograms of SFE extract of wheat germ (monitored at 220,240 and $295 \mathrm{~nm}$ ) after Saito et al. (1987). ${ }^{116}$ The chromatogram monitored at $295 \mathrm{~nm}$ represents the elution profile of tocopherols. 
HPLC.

Most recently, Vannoort et al. thoroughly reviewed the advances of SFE and its coupling with various chromatographic techniques. ${ }^{117}$

\section{Conclusion}

The advantages of coupling SFE/chromatography has been discussed and reviewed in light of analytical separation. So far, SFE and SFC have been developing separately, SFE in chemical engineering and SFC in analytical chemistry. In order to make faster progress in coupled SFE/SFC, the method can be accepted in chemical industry as well as analytical chemistry. However, it is most important to state that extensive interdisciplinary work must be carried out before this technique is accepted for practical purposes.

\section{References}

1. J. B. Hannay and J. Hogarth, Proc. R. Soc. London, 29, 324 (1879).

2. R. M. Smith ed., "Supercritical Fluid Chromatography", RSC Chromatography Monograph Series, Royal Society of Chemistry, London, 1988.

3. B. A. Charpentier and M. R. Sevenanto ed., "Supercritical Fluid Extraction and Chromatography, Techniques and Applications", ACS Symposium Series No. 366, American Chemical Society, Washington, D.C., 1988.

4. F. Yang ed., "Microbore Column Chromatography", Marcel Dekker, New York, 1989.

5. M. L. Lee and K. E. Markides ed., "Analytical Supercritical Fluid Chromatography and Extraction", Brigham Young University, Provo, 1990.

6. E. Klesper, A. H. Corwin and D. A. Turner, J. Org. Chem., 27, 700 (1962).

7. E. Klesper and W. Hartmann, J. Polym. Sci. Polym. Lett. Ed., 15, 9 (1977).

8. E. Klesper and W. Hartmann, J. Polym. Sci. Polym. Lett. Ed., 15, 77 (1977).

9. W. Hartmann and E. Klesper, J. Polym. Sci. Polym. Lett. Ed., 15, 713 (1977).

10. N. M. Myers and J. C. Giddings, Anal. Chem., 37, 1453 (1965).

11. N. M. Myers and J. C. Giddings, Anal. Chem., 38, 294 (1966).

12. M. N. Myers; J. C. Giddings, in E. S. Perry and C. J. Van Oss, Progress in Separation and Purification, 3, 133 (1970).

13. S. T. Sie, W. Van Beersum and G. W. A. Rijnders, Sep. Sci., 1, 459 (1966).

14. S. T. Sie and G. W. A. Rijnders, Sep. Sci., 2, 699 (1967).

15. S. T. Sie and G. W. A. Rijnders, Sep. Sci., 2, 729 (1967).

16. S. T. Sie and G. W. A. Rijnders, Sep. Sci, 2, 755 (1967).

17. S. T. Sie and G. W. A. Rijnders, Anal. Chim. Acta, 38, 31 (1967).

18. N. M. Karayannis, A. H. Corwin, E. W. Baker, E. Klesper and J. A. Walter, Anal. Chem., 40, 1736 (1968).

19. N. M. Karayannis, A. H. Corwin, Anal. Biochem., 26, 34 (1968).
20. N. M. Karayannis, A. H. Corwin, J. Chromatogr., 47, 247 (1970).

21. N. M. Karayannis, A. H. Corwin, J. Chromatogr. Sci., 8, 247 (1970).

22. J. C. Giddings, M. N. Myers and J. W. King, J. Chromatogr. Sci, 7, 276 (1969).

23. R. E. Jentoft and T. H. Gouw, J. Chromatogr. Sci., 8, 138 (1970).

24. R. E. Jentoft and T. H. Gouw, Anal. Chem., 44, 681 (1972).

25. M. Novotny, W. Bertsch and A. Zlatkis, J. Chromatogr., 61, 17 (1971).

26. D. Bartmann and G.M. Scheider, Chem.-Ing.-Tech., 42 , $702(1970)$.

27. D. Bartmann and G. M. Scheider, J. Chromatogr., 83, 135 (1973).

28. D. Bartmann, Ber. Bunsenges. Phys. Chem., 76, 336 (1972).

29. L. G. Randall, Sep. Sci., 17, 1 (1982).

30. T. H. Gouw and R. E. Jentoft, J. Chromatogr., 68, 303 (1972).

31. T. H. Gouw and R. E. Jentoft, Adv. Chromatogr., 13, 1 (1975).

32. T. H. Gouw, R. E. Jentoft and E. J. Gallegos, High Pressure Science and Technology, 1979, 583.

33. E. Klesper, Angew. Chem. Int. Ed. Engl., 17, 738 (1978).

34. U. Van Wasen, I. Swaid and G. M. Schneider, Angew. Chem. Int. Ed. Engl., 19, 575 (1980).

35. L. G. Randall, Sep. Sci., 17, 1 (1982).

36. M. Novotny, S. R. Springston, P. A. Peaden, J. C. Fjeldsted and M. L. Lee, Anal. Chem., 53, 407A (1981).

37. S. B. French and M. Novotny, Anal. Chem., 58, 164 (1986).

38. R. D. Smith, W. D. Felix, J. C. Fjeldsted and M. L. Lee, Anal. Chem., 54, 1883 (1982).

39. R. D. Smith, H. T. Kalinoski, H. R. Udseth and B. W. Wright, Anal. Chem., 56, 2476 (1984).

40. P. A. Peaden and M. L. Lee, J. Chromatogr., 259, 1 (1983).

41. S. R. Springston and M. Novotny, Anal. Chem., 56, 1762 (1984).

42. J. C. Fjeldsted and M. L. Lee, Anal. Chem., 56, 619A (1984).

43. Y. Hirata and F. Nakata, J. Chromatogr., 295, 315 (1984).

44. T. Takeuchi, D. Ishii, M. Saito and K. Hibi, J. Chromatogr., 295, 323 (1984).

45. P. A. Peaden and M. L. Lee, J. Liq. Chromatogr., 5, 179 (1982).

46. D. R. Gere, R. Board and D. McManigill, Anal. Chem., 54, 736 (1982).

47. T. A. Norris and M. G. Rawdon, Anal. Chem., 56, 1767 (1984).

48. M. G. Rawdon, Anal Chem., 56, 831 (1984).

49. M. Saito, K. Sugiyama, T. Hondo, M. Senda and S. Tohei, Abstracts of Papers, International HPLC Symposium Kyoto, January, 1985, Abstract p. 84.

50. K. Sugiyama, K. Saito, T. Hondo and M. Senda, $J$. Chromatogr., 332, 107 (1985).

51. K. Jinno, T. Hondo and M. Senda, Chromatographia, 21, 4, 219 (1986).

52. K. Jinno, T. Hoshino, T. Hondo M. Saito and M. Senda, Anal. Lett., 19, 1001 (1987).

53. K. Jinno, T. Hoshino, T. Hondo, M. Saito and $M$. Senda, Anal. Chem., 58, 2696 (1987). 
54. S. Hara, A. Dobashi, K.Kinoshita, T. Hondo, M. Saito and M. Senda, J. High Resolut. Chromatogr. Chromatogr. Commun., 9, 153 (1986).

55. S. Hara, A. Dobashi, K. Kinoshita, T. Hondo, M. Saito and M. Senda, J. Chromatogr., 371, 153 (1986).

56. J. B. Crowther, B. Jonathan and J. D. Henion, Anal. Chem., 57, 2711 (1985).

57. K. H. Shafer and P. R. Griffiths, Anal. Chem., 55, 1939 (1983).

58. S. V. Olesik, S. B. French and M. Novotny, Chromatographia, 18, 489 (1984).

59. C. C. Johnson, J. M. Jordan, L. T. Taylor and D. W. Vidrine, Chromatographia, 20, 717 (1985).

60. C. Fujimoto, Y. Hirata and K. Jinno, J. Chromatogr., 332, 47 (1985).

61. K. H. Shafer, S. L. Pentoney, Jr. and P. R. Griffiths, Anal. Chem., 58, 58 (1983).

62. D. E. Games, A. J. Berry, I. C. Mylchreest, J. R. Perkins and S. Pleasance, "Supercritical Fluid Chromatography", ed. R. M. Smith, Royal Society of Chemistry, London, 1988.

63. R. D. Smith, H. R. Udseth and B. W. Wright, J. Chromatogr. Sci, 23, 192 (1985).

64. K. Jinno, Chromatographia, 23, 55 (1987).

65. D. R. Luffer, L. J. Galante, P. A. David, M. Novotny and G. M. Hieftje, Anal. Chem., 60, 1365 (1988).

66. L. J. Galante, M. Selby, D. R. Luffer, G. M. Hieftje and M. Novotny, Anal. Chem., 60, 1370 (1988).

67. R. J. Skelton, Jr., P. B. Farnsworth, K. E. Markides and M. L. Lee, Anal. Chem., 61, 1815 (1989).

68. J. W. Olesik and S. V. Olesik, Anal. Chem., 59, 796 (1987).

69. C. Fujimoto, H. Yoshida and K. Jinno, J. Microcolumn Sep., 1, 19 (1989).

70. C. Fujimoto, H. Yoshida and K. Jinno, J. Chromatogr., 411, 123 (1987).

71. C. Fujimoto, H. Yoshida and K. Jinno, J. Microcolumn Sep., 2, 146 (1990).

72. K. A. Farbes, J. F. Vecchiarelli, P. C. Uden and B. M. Barnes, Anal. Chem., 62, 2033 (1990).

73. E. Klesper and W. Hartmann, Eur. Polym. J., 14, 2, 77 (1978).

74. R. M. Campbell and M. L. Lee, Anal. Chem., 58, 2247 (1986).

75. M. Nishioka, D. G. Whiting, R. M. Campbell and M. L. Lee, Anal. Chem., 58, 2251 (1986).

76. P. J. Schoenmakers and L. G. M. Uunk, Chromatographia, 24, 51 (1987).

77. M. Peterson, J. Chromatogr., 505, 3 (1990).

78. H. G. Janssen and C. A. Cramers, J. Chromatogr., 505, 19 (1990).

79. K. Zosel, Austrian Patent Application, 16. 4. 1963.

80. P. Hubert and O. G. Vitzthum, in "Extraction with Supercritical Gases", ed. G. M. Schneider, E. Stahl and G. Wilke, p. 25, Verlag Chemie, Weinheim, 1980.

81. S. Peter and G. Brunner, in "Extraction with Supercritical Gases", ed. G. M. Schneider, E. Stahl and G. Wilke, p. 141, Verlag Chemie, Weinheim, 1980.

82. R. Eggers and R. Tschiersch, in "Extraction with Supercritical Gases", ed. G.M. Schneider, E. Stahl and G. Wilke, p. 165, Verlag Chemie, Weinheim, 1980.

83. E. Stahl, E. Schutz and H. Mangold, J. Agric. Food Chem., 28, 1153 (1980).

84. E. Stahl and E. Schutz, Planta Med., 40, 262 (1980).

85. H. Coenen and P. Rinza, Tech. Mitt. Krupp-Werksber- ichte, 39 (1981) $\mathrm{H1}, \mathrm{Z1}$.

86. H. Brogle, Chem. Ind. [London], 19, 385 (1982).

87. R. P. de Filippi, Chem. Ind. [London], 19, 390 (1982).

88. T. R. Bott, Chem. Ind. [London], 19, 394 (1982).

89. R. Vollbrecht, Chem. Ind. [London], 19, 397 (1982).

90. J. P. Calame and R. Steiner, Chem. Ind. [London], 19, 399 (1982).

91. D. S. Gardner, Chem. Ind. [London], 19, 402 (1982).

92. J. P. Friedrich and E. H. Pryde, JAOCS, 61, 2, 223 (1984).

93. D. F. Williams, Chem. Eng. Sci., 36, 1769 (1981).

94. G. Brunner and S. Peter, Ger. Chem. Eng., 5, 181 (1982).

95. G. M. Schneider, E. Stahl and G. Wilke ed., "Extraction with Supercritical Gases", Verlag Chemie, Weinheim, 1980.

96. J. M. L. Penninger, M. Randoz, M. McHugh and V. J. Krukonis, ed, "Supercritical Fluid Technology", Elsevier, Amsterdam, 1985.

97. M. McHugh and V. Krukonis, "Supercritical Fluid Extraction", Butterworths, Massachusetts, 1986.

98. K. Zosel, Austrian Patent Application, 16. 4. 1963.

99. K. Arai and S. Saito, Presented at World Congress IIl of Chemical Engineering, No. 7a-304, September, 1986, Tokyo, Japan.

100. S. B. Hawthorne, Anal. Chem., 62, 633A (1990).

101. T. L. Chester and J. D. Pinkston, Anal. Chem., 62, 394R (1990).

102. E. Stahl and W. Schilz, Fresenius' Z. Anal. Chem., 280, 99 (1976).

103. E. Stahl, J. Chromatogr., 142, 15 (1977).

104. K. K. Unger and P. Roumeliotis, J. Chromatogr., 282, 519 (1983).

105. S. B. Hawthorne and D. J. Miller, J. Chromatogr., 403, 63 (1987).

106. B. R. Wright, S. R. Frye, D. G. McMinn and R. D. Smith, Anal. Chem., 59, 640 (1987).

107. M. Saito, T. Hondo, Y. Yamauchi, M. Kuwajima, E. Tanigawa and M. Senda, Proceedings of 11 th International Symposium on Capillary Chromatography, Gifu, Japan, 1986.

108. T. Hoshino, M. Senda, T. Hondo, M. Saito, S. Tohei, J. Chromatogr., 316, 473 (1984).

109. T. Hoshino, T. Hondo, M. Senda, M. Saito, S. Tohei, J. Chromatogr., 332, 139 (1985).

110. K. Sugiyama, M. Saito, A. Wada, M. Senda, S. Tohei, Pittsburgh Conference Abstracts, No. 541, 1986.

111. T. Imahashi, Y. Yamauchi and M. Saito, Bunseki Kagaku, 38, 79 (1989).

112. T. Hondo, M. Saito and M. Senda, Bunseki Kagaku, 35, 316 (1986).

113. M. Saito and T. Hondo, Yukagaku, 35, 273 (1986).

114. M. Saito, T. Hondo and M. Senda, in "Multidimensional Chromatography”, ed. H. Cortes, Marcel Dekker, New York, 1990.

115. M. Perrut and P. Jusforgues, Entropie, 132, 2 (1986).

116. M. Saito, T. Hondo and Y. Yamauchi, in "Supercritical Fluid Chromatography", ed. R. Smith, Royal Society of Chemistry, London, 1987.

117. R. W. Vannoort, J. P. Chervet, H. Lingeman, G. J. deJong and U. A. Brinkman, J. Chromatogr, 505, 45 (1990).

(Received October 2, 1990)

(Accepted November 14, 1990) 